\title{
Caracterização morfoagronômica de genótipos de feijoeiro comum quanto à precocidade
}

\author{
Morpho-agronomic characterization of common bean genotypes regarding precocity \\ Caracterización morfoagronómica de genotipos de frijol común con respecto a la precocidad
}

Ana Paula Sandoval Rodrigues ORCID: https://orcid.org/0000-0002-7811-3000 Universidade do Estado de Mato Grosso, Brasil E-mail: paula_gtaa@hotmail.com

Taniele Carvalho de Oliveira ORCID: https://orcid.org/0000-0002-6900-6449 Universidade do Estado de Mato Grosso, Brasil

E-mail: taniele.carvalho@unemat.br

Altacis Junior de Oliveira ORCID: https://orcid.org/0000-0002-6787-7160 Universidade do Estado de Mato Grosso, Brasil

E-mail: juniormarque11@gmail.com Andressa Alves Cabreira dos Santos ORCID: https://orcid.org/0000-0001-6731-9575 Universidade do Estado de Mato Grosso, Brasi

E-mail: acabreyra@gmail.com

Mirian da Silva Almici

ORCID: https://orcid.org/0000-0001-9467-7060 Universidade do Estado de Mato Grosso, Brasil

E-mail: mirianalmici@hotmail.com

Valvenarg Pereira da Silva ORCID: https://orcid.org/0000-0001-8450-3016 Universidade do Estado de Mato Grosso, Brasil

E-mail: silvabiologo@hotmail.com

Lucas Henrique Pereira Morais ORCID: https://orcid.org/0000-0002-3251-5821 Universidade do Estado de Mato Grosso, Brasil E-mail: lucas.morais@unemat.br

Anelise Saldanha Carneiro Pires ORCID: https://orcid.org/0000-0002-4475-5742 Universidade do Estado de Mato Grosso, Brasil

E-mail: anelisesaldanha2016@gmail.com

Felipe Romanzini Duran Lima ORCID: https://orcid.org/0000-0001-8551-2221 Universidade do Estado de Mato Grosso, Brasil E-mail: felipe.romanzini@unemat.br

Vinícius Souza da Silva

ORCID: https://orcid.org/0000-0003-2502-6381 Universidade do Estado de Mato Grosso, Brasil E-mail: vinicius.souza.silva@ unemat.br

Geovane José da silva

ORCID: https://orcid.org/0000-0001-5948-2663 Universidade do Estado de Mato Grosso, Brasil E-mail: geovane.silva@unemat.br

Gabrielly Andrade Miranda ORCID: https://orcid.org/0000-0001-5781-7976 Universidade do Estado de Mato Grosso, Brasil E-mail: gabizandrade17@gmail.com

Marco Antonio Aparecido Barelli ORCID: https://orcid.org/0000-0002-6385-6733 Universidade do Estado de Mato Grosso, Brasil E-mail: mbarelli@unemat.br

\section{Resumo}

O feijoeiro comum é uma cultura de grande importância alimentar, econômica e social, em termos de produção e consumo, é uma leguminosa herbácea, com ciclo em torno de 95 dias, a maioria das cultivares utilizadas para o 
cultivo no mercado brasileiro expressa grande variabilidade genéticas quanto ao início de florescimento e a duração total do ciclo. Diante disso, objetivou-se com este trabalho avaliar a caracterização morfoagronômica de genótipos de feijoeiro comum quanto à precocidade de cultivo. O experimento foi conduzido na EMAPER, no município de Cáceres-MT, adotando o delineamento experimental em blocos ao acaso com três repetições, avaliando 58 genótipos de feijão comum. As parcelas foram compostas por quatro linhas de $4 \mathrm{~m}$, com espaçamento de $0,5 \mathrm{~m}$ entre linhas. As características avaliadas foram o número de dias para o florescimento e ciclo de cultivo, os dados foram submetidos à análise de variância e a comparação das medias pelo teste de agrupamento Scott-Knott a $1 \%$ de probabilidade. A divergência genética foi estimada método de otimização de Tocher e hierárquico UPGMA, baseada na Distância Generalizada de Mahalanobis utilizando o programa computacional GENES. Pode-se concluir que existe variabilidade genética entre os genótipos de feijão comum avaliados, e os genótipos 3 (BG-UNEMAT-11) e 57 (TB 02-23) apresentaram menor número de dias para florescimento (31 dias) e menor ciclo da cultura (73 a 82 dias), sendo os mais indicados para programas de melhoramento genético visando precocidade.

Palavras-chave: Ciclo; Divergência Genética; Floração.

\begin{abstract}
The common bean is a crop of great food, economic and social importance, in terms of production and consumption, it is an herbaceous legume, with a cycle around 95 days. Most cultivars used for cultivation in the Brazilian market express great genetic variability as to the onset of flowering and total cycle length. Therefore, the objective of this work was to evaluate the morphological and agronomic characterization of common bean genotypes regarding the precocity of cultivation. The experiment was conducted in EMAPER, in the city of Cáceres-MT, adopting the experimental design in randomized blocks with three repetitions, evaluating 58 common bean genotypes. The plots were composed of four rows of $4 \mathrm{~m}$, with spacing of $0.5 \mathrm{~m}$ between rows. The evaluated characteristics were the number of days to flowering and crop cycle, the data were subjected to analysis of variance and comparison of means by the Scott-Knott grouping test at $1 \%$ probability. The genetic divergence was estimated by Tocher's optimization method and hierarchical UPGMA, based on the Generalized Mahalanobis Distance using the computer program GENES. It can be concluded that there is genetic variability among the evaluated common bean genotypes, and the genotypes 3 (BG-UNEMAT-11) and 57 (TB 02-23) showed fewer days to flowering (31 days) and shorter crop cycle (73 to 82 days), being the most suitable for breeding programs aiming precocity.
\end{abstract}

Keywords: Cycle; Genetic Divergence; Flowering.

\title{
Resumen
}

El frijol común es un cultivo de gran importancia alimentaria, económica y social, en términos de producción y consumo, es una leguminosa herbácea, con ciclo alrededor de 95 días, la mayoría de los cultivares utilizados para el cultivo en el mercado brasileño expresa una gran variabilidad genética como el inicio de la floración y la duración total del ciclo. Por lo tanto, este trabajo tuvo como objetivo evaluar la caracterización morfológica y agronómica de los genotipos de frijol común con respecto a la precocidad del cultivo. El experimento se realizó en EMAPER, en el municipio de Cáceres-MT, adoptando el diseño experimental en bloques al azar con tres repeticiones, evaluando 58 genotipos de judía común. Las parcelas estaban compuestas por cuatro filas de $4 \mathrm{~m}$, con una separación de $0,5 \mathrm{~m}$ entre filas. Los caracteres evaluados fueron el número de días a la floración y el ciclo del cultivo, los datos fueron sometidos a análisis de varianza y comparación de medias mediante la prueba de agrupación de Scott-Knott al 1\% de probabilidad. La divergencia genética se estimó mediante el método de optimización de Tocher y el UPGMA jerárquico, basado en la Distancia de Mahalanobis Generalizada, utilizando el programa informático GENES. Se puede concluir que existe variabilidad genética entre los genotipos de frijol común evaluados, y que los genotipos 3 (BG-UNEMAT-11) y 57 (TB 02-23) mostraron menos días a la floración (31 días) y un ciclo de cultivo más corto (73 a 82 días), siendo los más adecuados para los programas de mejoramiento que buscan la precocidad.

Palabras clave: Ciclo; Divergencia genética; Floración.

\section{Introdução}

O feijoeiro comum (Phaseolus vulgaris L.) é uma cultura de grande importância alimentar, econômica e social, em termos de produção e consumo, o Brasil se destaca como maior produtor e consumidor mundial (FAO, 2019). Segundo a CONAB (2020) a estimativa de produção brasileira no ano de 2020 foi de 3,2 milhões de toneladas, sendo 0,5 milhão de toneladas de feijão preto, 2 milhões de toneladas de feijão de cores, que inclui os feijões carioca e especial (CONAB, 2020).

A cultura é uma leguminosa herbácea, com ciclo em torno de 95 dias, caracteriza-se por uma dependência extrema das condições meteorológicas favoráveis para o perfeito desenvolvimento, especialmente em relação ao déficit hídrico, que representa um dos fatores limitantes para obtenção de alta produtividade (Lopes et al., 1986). A cultura se adapta a diferentes 
condições climáticas com temperatura ideal para o cultivo variando entre $21^{\circ} \mathrm{C}$ a $29^{\circ} \mathrm{C}$, permitindo o seu cultivo durante todo o ano, em quase todos os estados brasileiros, possibilitando uma constante oferta do produto no mercado (Bonett et al., 2006; Silva et al., 2005).

O Brasil possui uma diversidade de cultivares de feijoeiro de diferentes grupos comerciais, como o carioca, o preto e o especial. O feijão carioca é o mais cultivado no Brasil, com $70 \%$ da produção, seguido pelo feijão preto e especiais (Chiorato et al., 2020 a,b). A maior parte das cultivares de feijoeiro oferecido para o cultivo no mercado brasileiro expressa grande variabilidade genéticas quanto ao início de florescimento e a duração total do ciclo. Com o emprego de materiais precoces nos mercados (maturação de colheita de 60 - 75 dias após o plantio) os produtores têm melhor aproveitamento da área de cultivo, além de poder adequar a época mais favorável para o plantio e colheita, com base no conhecimento das condições ambientais que predomina na região de cultivo (Ribeiro et al., 2004).

O melhoramento genético dessas cultivares tem proporcionado características agronômicas desejáveis, como à precocidade de ciclo e de florescimento. Completando assim o ciclo em um menor espaço de tempo evitando estresses ambientais (déficit hídrico, temperaturas muito altas ou baixas, luminosidade, etc.), proporcionando ganhos na produtividade de grãos. E com isso mudando o perfil do sistema produtivo e estimulando à iniciativa empresarial para a produção em grande escala (Frota et al., 2000). A busca por cultivares precoces tem sido o objetivo de muitos programas de melhoramento, onde a precocidade é definida como a capacidade das plantas em completar o seu ciclo, em período menor que aquele considerado normal ou médio, variedades 80-90 dias para feijoeiro (Costa \& Zimmermann, 1988).

A principal característica utilizada para avaliar a precocidade de uma cultura é o florescimento, ou seja, o tempo decorrido entre a semeadura e a abertura de 50\% das primeiras flores por parcela. Outra característica ligada diretamente com a precocidade da cultura é o período correspondente entre a semeadura e a maturidade fisiológica das sementes (Buratto et al. 2007; Silva et al., 2007; Ribeiro et al., 2004). De acordo com Buratto et al. (2007), a precocidade nas cultivares de feijoeiro comum apresentam diversas vantagens, tais como: escape de estresse climático, menor consumo de água e de tempo de uso do solo em cultivos irrigados e intensivos, redução de perdas na colheita, fazendo a coincidir com épocas menos chuvosas e favorecimento para a rotação de culturas.

A utilização de cultivares precoce possibilita a semeadura no período das águas, disponibilizando área para o cultivo de outras culturas em período favorável no decorrer do ano. Com a semeadura antecipada do feijão comum pode-se prevenir exposição da cultura a geada, além de, possibilita ao agricultor obter melhor preço de venda (Dalla Corte et al., 2002). Em vista do exposto, objetivou-se com este trabalho avaliar a caracterização morfoagronômica de genótipos de feijoeiro comum quanto à precocidade de cultivo.

\section{Metodologia}

O experimento foi conduzido no Centro de Pesquisa e Extensão da Empresa Mato-Grossense de Pesquisa, Assistência e Extensão Rural (EMPAER), no município de Cáceres - MT, com latitude de $16^{\circ} 13^{\prime} 42^{\prime}$ ' S e longitude de 57 40'05" W, à 118 metros de altitude. O solo foi classificado como Argissolo Vermelho Amarelo Eutrófico Chernossólico, textura média argilosa nos horizontes A e B respectivamente (Santos et al., 2006), com declividade de $2 \%$.

As condições climáticas características da região variam de quente e úmida, com regime de chuvas de novembro a março e regime de seca de maio a setembro. A região apresenta temperaturas elevadas praticamente o ano todo, onde a temperatura máxima pode chegar a $41,2{ }^{\circ} \mathrm{C}$, a média é de temperatura de $26,24^{\circ} \mathrm{C}$ e com precipitação total anual de $1.335 \mathrm{~mm}$ (Neves et al., 2011).

Foram utilizados 58 genótipos de feijoeiro comum, sendo estes 40 pertencentes à coleção de Germoplasma do 
Laboratório de Recursos Genéticos \& Biotecnologia da Universidade do Estado de Mato Grosso - UNEMAT, campus de Cáceres e 18 linhagens melhoradas do Regional Sul do Feijão. Sendo a maioria dos genótipos pertencentes ao grupo gênico Mesoamericano e os genótipos 3, 20, 34, 35 e 57 são pertencentes ao grupo gênico Andino (Tabela 1).

Tabela 1. Identificação dos genótipos de feijão comum avaliados.

\begin{tabular}{|c|c|c|c|c|c|c|c|c|c|}
\hline $\mathrm{N}^{\circ}$ & Genótipo & $\mathrm{N}^{\circ}$ & Genótipo & $\mathrm{N}^{\circ}$ & Genótipo & $\mathrm{N}^{\circ}$ & Genótipo & $\mathrm{N}^{\circ}$ & Genótipo \\
\hline 1 & BG-UNEMAT-18 & 13 & BG-UNEMAT-29 & 25 & BG-UNEMAT-49 & 37 & BG-UNEMAT-12 & 49 & CNFC 10762 \\
\hline 2 & BG-UNEMAT-28 & 14 & BG-UNEMAT-35 & 26 & BG-UNEMAT-45 & 38 & BG-UNEMAT-13 & 50 & CNFP 10794 \\
\hline 3 & BG-UNEMAT-11 & 15 & BG-UNEMAT-42 & 27 & BG-UNEMAT-46 & 39 & BG-UNEMAT-20 & 51 & FT 08-47 \\
\hline 4 & BG-UNEMAT-27 & 16 & BG-UNEMAT-23 & 28 & BG-UNEMAT-72 & 40 & BG-UNEMAT-21 & 52 & FT $08-75$ \\
\hline 5 & BG-UNEMAT-22 & 17 & BG-UNEMAT-26 & 29 & BG-UNEMAT-55 & 41 & Pérola & 53 & LEC 01-11 \\
\hline 6 & BG-UNEMAT-40 & 18 & BG-UNEMAT-31 & 30 & BG-UNEMAT-16 & 42 & IPR Campos Gerais & 54 & LEP 02-11 \\
\hline 7 & BG-UNEMAT-17 & 19 & BG-UNEMAT-37 & 31 & BG-UNEMAT-60 & 43 & IPR UIRAPURU & 55 & LP 09-192 \\
\hline 8 & BG-UNEMAT-32 & 20 & BG-UNEMAT-38 & 32 & BG-UNEMAT-58 & 44 & CNFP 10104 & 56 & LP 09-40 \\
\hline 9 & BG-UNEMAT-4 & 21 & BG-UNEMAT-75 & 33 & BG-UNEMAT-5 & 45 & C $4-7-7-2-2$ & 57 & TB $02-23$ \\
\hline 10 & BG-UNEMAT-30 & 22 & BG-UNEMAT-1 & 34 & BG-UNEMAT-68 & 46 & C4-7-8-1- 2 & 58 & ТВ 03-13 \\
\hline 11 & BG-UNEMAT-3 & 23 & BG-UNEMAT-56 & 35 & BG-UNEMAT-7 & 47 & CHC 98-42 & & \\
\hline 12 & BG-UNEMAT-6 & 24 & BG-UNEMAT-50 & 36 & BG-UNEMAT-47 & 48 & CHP 01-238 & & \\
\hline
\end{tabular}

Fonte: Autores (2014).

Os genótipos avaliados foram implantados adotando o delineamento experimental de blocos ao acaso (DBC), com três repetições, onde as parcelas experimentais foram compostas por quatro linhas de quatro metros, com espaçamento de 0,50 metros entre linhas. Foram consideradas apenas as duas fileiras centrais como área útil de cada parcela, densidade de semeadura de dez sementes por metro linear.

O preparo da área constou de duas gradagens e uma niveladora com a finalidade de nivelar e destorroar o terreno, em seguida foi feito a abertura mecânica dos sulcos com um sulcador de cinco hastes, acoplado ao trator. Foram utilizados $350 \mathrm{~kg}$ $\mathrm{ha}^{-1}$ do formulado 8-28-16 (N-P-K) de adubo durante o plantio, o controle de insetos e de plantas invasoras foram realizados sempre que necessário, a fim de não comprometer o desenvolvimento da cultura. A irrigação foi realizada por aspersão sempre que necessário, com o objetivo de manter as condições de umidade ideais para o desenvolvimento da cultura.

As características avaliadas foram:

a) Número médio de dias para o florescimento (FLORESC): obtido pela contagem do número de dias desde a semeadura até à abertura completa das flores de 50\% das plantas de cada parcela;

b) Ciclo da planta (CICLO): obtido pela contagem do número de dias da semeadura até a maturação fisiológica (quando pelo menos 90\% das vagens em cada tratamento estivessem maduras);

Os dados obtidos para cada característica foram submetidos à análise de variância e a comparação das medias foram realizadas pelo teste de agrupamento Scott-Knott, ao nível de 1\% de probabilidade. Para determinar a divergência genética entre os genótipos, empregou-se o método de agrupamento de otimização de Tocher (Rao, 1952) e o método hierárquico de Agrupamento Médio Entre Grupos (UPGMA), através da matriz de dissimilaridade, baseada na Distância Generalizada de Mahalanobis. Os procedimentos estatísticos foram realizados por meio do programa computacional GENES (Cruz, 2013). 


\section{Resultados e Discussão}

Foram observadas diferenças significativas a $1 \%$ de probabilidade pelo teste $\mathrm{F}$ para as características avaliadas, indicando que os genótipos de feijão comum apresentaram comportamento distintos para florescimento e ciclo (Tabela 2). $\mathrm{O}$ coeficiente de variação CV (\%) foram baixos, indicando precisão experimental adequada, pois Cargnelutti Filho et al. (2006) avaliando 14 cultivares de feijoeiro, obtiveram CV de 3,57\% e 1,86\% para as características Florescimento e Ciclo da cultura, respectivamente. Resultados semelhantes foram obtidos também por Faria et al. (2009) avaliando 20 genótipos de feijoeiro, obtiveram um CV de 0,9\% e 1,3\% para as características Florescimento e Ciclo da cultura, demostrando que os resultados do presente trabalho se encontram dentro do esperado para as características avaliadas.

Tabela 2. Significâncias dos Quadrados Médios (QM) e coeficientes da variação experimental (CV) para as duas características avaliadas, em 58 genótipos de feijoeiro (Cáceres-MT, 2014).

\begin{tabular}{cccc}
\hline \multirow{2}{*}{ FV } & GL & \multicolumn{3}{c}{ QUADRADOS MÉDIOS } \\
\cline { 3 - 4 } & & FLORESC & CICLO \\
\hline BLOCOS & 2 & 0,3621 & 12,1609 \\
GENÓTIPOS & 57 & $13,7787^{* *}$ & $317,2382^{* *}$ \\
RESÍDUO & 114 & 0,5960 & 11,5176 \\
\hline MÉDIA & & 37,29 & 84,98 \\
CV \% & & 2,07 & 3,99 \\
\hline
\end{tabular}

** Significativo a $1 \%$ de probabilidade, pelo teste F. Fonte: Autores (2014).

Na Tabela 3 estão os valores obtidos pelo teste de agrupamento de Scott-Knott entre os genótipos para as características avaliadas. Para a característica FLORESC os genótipos floriram em média com 37,29 dias após a semeadura e permitiu a divisão dos mesmos em cinco grupos, variando de 31 a 40 dias para florescimento entre os genótipos avaliados.

Em relação ao ciclo da planta, os genótipos também foram divididos em cinco grupos distintos, apresentando variação de 73 a 100 dias. Os genótipos classificados como mais precoces foram (1, 2, 3, 4, 8, 9, 11, 13, 14, 16, 18, 23,25, 26, 27, 28, 30,31, 32 e 33) apresentando um ciclo inferior a 78 dias. Os genótipos que levaram maior período para desenvolvimento foram $41,42,43,44,45,46,47,48,49,50,51,52,53,54,55$ e 56, com ciclo superior a 99 dias. Já os genótipos 5, 6, 7, 10, 12, 17, 19, 20, 21, 22, 24, 25 29, 34, 35, 36, 37, 38, 39, 40, 57 e 58, apresentaram um ciclo intermediário variando de 79 a 92 dias.

A precocidade de cultivares e a redução do ciclo de cultivo são características que os produtores buscam cada vez mais, pois podem adaptarem melhor às lavouras em sistemas de rotação e consorciação, economizando água e energia nos sistemas de irrigação, além do retorno de investimento é mais rápido. Os resultados obtidos neste trabalho aproximaram-se aos valores encontrados por Buratto et al. (2007), avaliando 20 genótipos de feijão comum para adaptabilidade e estabilidade produtiva em genótipos precoces no estado do Paraná. Já Cargnelutti Filho et al. (2008) avaliando 14 cultivares de feijão comum obtiveram valores médio de números de dias para florescimento em torno de 36,99 dias e o ciclo da planta 77,19 dias. 
Tabela 3. Comparação das médias das características número de dias para o florescimento (FLORESC) e Ciclo da planta (CICLO) avaliadas em 58 genótipos de feijoeiro pelo método de Scott-Knott (Cáceres-MT, 2014).

\begin{tabular}{|c|c|c|c|c|c|c|c|c|}
\hline $\mathrm{N}^{\circ}$ & FLORESC & CICLO & $\mathrm{N}^{\circ}$ & FLORESC & CICLO & $\mathrm{N}^{\circ}$ & FLORESC & CICLO \\
\hline 1 & $36,333 \mathrm{c}$ & $78,000 \mathrm{e}$ & 21 & $38,000 \mathrm{~b}$ & $82,667 \mathrm{~d}$ & 41 & $39,000 \mathrm{a}$ & $100,667 \mathrm{a}$ \\
\hline 2 & $35,000 \mathrm{c}$ & $74,333 \mathrm{e}$ & 22 & $39,000 \mathrm{a}$ & $82,000 \mathrm{~d}$ & 42 & $39,667 \mathrm{a}$ & $99,000 \mathrm{a}$ \\
\hline 3 & $31,000 \mathrm{e}$ & $73,000 \mathrm{e}$ & 23 & $36,333 \mathrm{c}$ & $75,667 \mathrm{e}$ & 43 & $39,667 \mathrm{a}$ & $100,667 \mathrm{a}$ \\
\hline 4 & $37,000 \mathrm{c}$ & $73,000 \mathrm{e}$ & 24 & $39,000 \mathrm{a}$ & $86,667 \mathrm{c}$ & 44 & $38,000 \mathrm{~b}$ & $99,000 \mathrm{a}$ \\
\hline 5 & $39,000 \mathrm{a}$ & $87,667 \mathrm{c}$ & 25 & $37,000 \mathrm{c}$ & $75,667 \mathrm{e}$ & 45 & $39,333 \mathrm{a}$ & $100,667 \mathrm{a}$ \\
\hline 6 & $39,000 \mathrm{a}$ & $88,667 \mathrm{~b}$ & 26 & $35,667 \mathrm{c}$ & $74,333 \mathrm{e}$ & 46 & $39,000 \mathrm{a}$ & $100,667 \mathrm{a}$ \\
\hline 7 & $38,667 \mathrm{a}$ & $87,667 \mathrm{c}$ & 27 & $34,333 \mathrm{~d}$ & $73,000 \mathrm{e}$ & 47 & $39,000 \mathrm{a}$ & $99,000 \mathrm{a}$ \\
\hline 8 & $36,667 \mathrm{c}$ & $73,000 \mathrm{e}$ & 28 & $36,333 \mathrm{c}$ & $74,333 \mathrm{e}$ & 48 & $39,000 \mathrm{a}$ & $99,000 \mathrm{a}$ \\
\hline 9 & $36,667 \mathrm{c}$ & $73,000 \mathrm{e}$ & 29 & $38,000 \mathrm{~b}$ & $82,000 \mathrm{~d}$ & 49 & $39,667 \mathrm{a}$ & $99,000 \mathrm{a}$ \\
\hline 10 & $39,000 \mathrm{a}$ & $87,667 \mathrm{c}$ & 30 & $35,667 \mathrm{c}$ & $75,667 \mathrm{e}$ & 50 & $38,000 \mathrm{~b}$ & $99,000 \mathrm{a}$ \\
\hline 11 & $35,333 \mathrm{c}$ & $73,000 \mathrm{e}$ & 31 & $35,667 \mathrm{c}$ & $78,000 \mathrm{e}$ & 51 & $40,333 \mathrm{a}$ & $99,000 \mathrm{a}$ \\
\hline 12 & $36,000 \mathrm{c}$ & $79,333 \mathrm{~d}$ & 32 & $35,333 \mathrm{c}$ & $73,000 \mathrm{e}$ & 52 & $39,000 \mathrm{a}$ & $99,000 \mathrm{a}$ \\
\hline 13 & $35,333 \mathrm{c}$ & $73,000 \mathrm{e}$ & 33 & $36,667 \mathrm{c}$ & $75,667 \mathrm{e}$ & 53 & $39,000 \mathrm{a}$ & $99,000 \mathrm{a}$ \\
\hline 14 & $36,333 \mathrm{c}$ & $73,000 \mathrm{e}$ & 34 & $35,667 \mathrm{c}$ & $80,333 \mathrm{~d}$ & 54 & $39,333 \mathrm{a}$ & $99,000 \mathrm{a}$ \\
\hline 15 & $40,000 \mathrm{a}$ & $85,000 \mathrm{c}$ & 35 & $35,333 \mathrm{c}$ & $79,333 \mathrm{~d}$ & 55 & $39,667 \mathrm{a}$ & $99,000 \mathrm{a}$ \\
\hline 16 & $33,333 \mathrm{~d}$ & $73,000 \mathrm{e}$ & 36 & $38,000 \mathrm{~b}$ & $92,000 \mathrm{~b}$ & 56 & $39,000 \mathrm{a}$ & $100,667 \mathrm{a}$ \\
\hline 17 & $39,000 \mathrm{a}$ & $84,333 \mathrm{c}$ & 37 & $38,000 \mathrm{~b}$ & $82,667 \mathrm{~d}$ & 57 & $31,000 \mathrm{e}$ & $82,000 \mathrm{~d}$ \\
\hline 18 & $36,000 \mathrm{c}$ & $74,333 \mathrm{e}$ & 38 & $37,333 \mathrm{~b}$ & $81,667 \mathrm{~d}$ & 58 & $34,000 \mathrm{~d}$ & $82,000 \mathrm{~d}$ \\
\hline 19 & $38,667 \mathrm{a}$ & $90,333 \mathrm{~b}$ & 39 & $38,667 \mathrm{a}$ & $79,333 \mathrm{~d}$ & & & \\
\hline 20 & $34,000 \mathrm{~d}$ & $85,333 \mathrm{c}$ & 40 & $39,000 \mathrm{a}$ & $81,667 \mathrm{~d}$ & & & \\
\hline
\end{tabular}

Fonte: Autores (2014).

Por meio da matriz de dissimilaridade, baseada na distância de Mahalanobis $\left(D^{2}{ }_{i i}\right)$, pode-se verificar que a combinação mais divergente ocorreu entre os genótipos 3 e 43 com valor de dissimilaridade de $D_{i i}^{2}$, $=229,417 \%$ e entre os genótipos 3 e $51\left(D_{i i}^{2}=242,518 \%\right)$, sendo que o genótipo 3 faz parte do grupo gênico Andino e os genótipos 43 e 51 do grupo gênico Mesoamericano. O menor valor de dissimilaridade $\left(D^{2}{ }_{i i},=0,00 \%\right)$ foi entre os genótipos 5 e 10,8 e 9,13 e 32,21 e 37 , 44 e 50,49 e 55, 52 e 53, 11 combinando com o 13 e o 32, 41 com o 46 e o 56, 42 com o 49 e o 55 , 46 com o 56 e o 53,47 com o 48 e o 52, 48 com o 52 e o 53, que apresentaram mais similaridade dentre os demais analisados por serem do grupo gênico Mesoamericano.

Segundo Oliveira et al. (2003), a grande amplitude de $D^{2}{ }_{i i}$, e os altos valores estimados para a maioria dos pares de cultivares revelam a grande variabilidade genética existente neste grupo de genótipos, o que torna possível a identificação de genitores para a formação de uma população com uma ampla base genética, aumentando assim, a probabilidade de obtenção de genótipos superiores nas gerações segregantes.

A análise realizada pelo método de agrupamento de Tocher possibilitou a divisão dos genótipos em seis grupos distintos (Tabela 4), de forma a alocar os genótipos mais divergentes em grupos diferentes. O grupo I, II e III foram compostos por um maior número de genótipos, com $27,2 \%, 36,2 \%$ e 27,2\% dos genótipos avaliados, respectivamente. 
Tabela 4. Representação do agrupamento gerado pelo método de otimização de Tocher com base na dissimilaridade entre os 58 genótipos de feijão comum (Cáceres - MT, 2014).

\begin{tabular}{ccc}
\hline GRUPO & GENÓTIPOS & \% DE GENÓTIPOS \\
\hline I & $5,10,6,24,7,19,17,15,22,40,21,37,29,39,36$ e 38 & 27,6 \\
II & $8,9,4,14,28,33,23,18,25,1,30,26,31,12,11,13,32,2,35,34$ e 27 & 36,2 \\
III & $41,46,56,45,47,48,52,53,54,42,49,55,43,51,44$ e 50 & 27,6 \\
IV & 20 e 58 & 3,4 \\
V & 3 e 57 & 3,4 \\
VI & 16 & 1,7 \\
\hline TOTAL & 58 & 100,0 \\
\hline
\end{tabular}

Fonte: Autores (2014).

Os demais grupos formados alocaram poucos genótipos cada, onde o grupo IV e V foram compostos por apenas dois genótipos $(3,4 \%)$ e o grupo VI apenas pelo genótipo $16(1,7 \%)$, neste caso é possível afirmar que estes genótipos são os mais dissimilares em relação aos demais. Resultados semelhante foram verificados por Ribeiro et al. (2005) analisando 220 genótipos de feijão comum pelo realizado o método Tocher separadamente para os 83 do grupo comercial preto e 137 de cor, separando assim em grupos com número de representação diferenciados, sendo a grande maioria foram ordenados nos três primeiros grupos e alguns genótipos isolados em grupos distinto.

A partir do método de otimização de Tocher foi determinado à distância média intra e intergrupos (Tabela 5), a maior distância média intragrupo foi observada no grupo $\mathrm{V}(\mathrm{dV}=7,23)$, enquanto que a menor distância intragrupo foi o grupo IV $(\mathrm{dIV}=0,99)$. Em relação à distância intergrupo o maior valor foi observado entre os grupos III e V (dIII; V = 184,42), no entanto à distância intergrupo de menor proporção foi verificado entre o grupo V e VI ( dV;VI = 11,64).

Tabela 5. Distância média intra e intergrupos estimados pelo método de otimização de Tocher com base na dissimilaridade entre os 58 genótipos de feijoeiro (Cáceres - MT, 2014).

\begin{tabular}{ccccccc}
\hline & I & II & III & IV & V & VI \\
\hline I & 3,88 & 28,12 & 22,41 & 40,39 & 117,35 & 72,10 \\
II & & 2,73 & 83,10 & 12,28 & 44,15 & 14,17 \\
III & & 1,35 & 80,13 & 184,42 & 142,45 \\
IV & & & 0,99 & 23,41 & 12,11 \\
V & & & & 7,23 & 11,64 \\
VI & & & & & & - \\
\hline
\end{tabular}

Fonte: Autores (2014).

As distância intergrupos fornecem resultados úteis para escolha de genitores para cruzamentos, sugerindo que a descendência do cruzamento entre os genótipos dos grupos III e V (grupo mais divergente) poderá apresentar uma base genética mais ampla e maior possibilidade de obtenção e seleção de genótipos desejados pelo melhorista, quando comparada entre os genótipos descendentes dos grupos III e IV (grupo menos divergente) podendo reduzir a possibilidade de obtenção de genótipos superiores.

Resultados semelhantes foram encontrados por Kvitschal (2008), avaliando s caracterização morfoagronômica e a 
divergência genética em germoplasma de mandioca-de-mesa onde os métodos de agrupamento alacaram os acessos previamente definidos como mais divergentes de forma isolada em grupos distintos, separando os mesmos em grupos para os métodos de UPGMA e Tocher, além de separar intergrupo e intragrupo entre os grupos mais divergentes e os mais similares.

O agrupamento realizado pelo método Hierárquico UPGMA submetido a um corte de $40 \%$ apresentou a formação de três grupos distintos (Figura 1). O grupo I foi formado por 32 dos 58 genótipos avaliados resultante da junção dos genótipos do grupo I e III gerado pelo método de Tocher, apresentando 37,33 a 40,33 dias para florescimento e ciclo mais tardio. O grupo II, formados por apenas dois genótipos (BG-UNEMAT - 11 e TB 02-23), foi semelhante ao grupo V do método de Tocher, tendo como a principal característica o menor número de dias para florescimento (31 dias) e menor ciclo (variando de 73 a 82 dias), já o grupo III foi constituído por 24 genótipos, apresentando 33 a 37 dias para florescimento e ciclo variando entre 73 a 85 dias.

Figura 1. Dendrograma representativo do agrupamento de 58 genótipos de feijoeiro, pelo Método UPGMA, com base na dissimilaridade estimada a partir das características analisadas (Cáceres-MT, 2014).

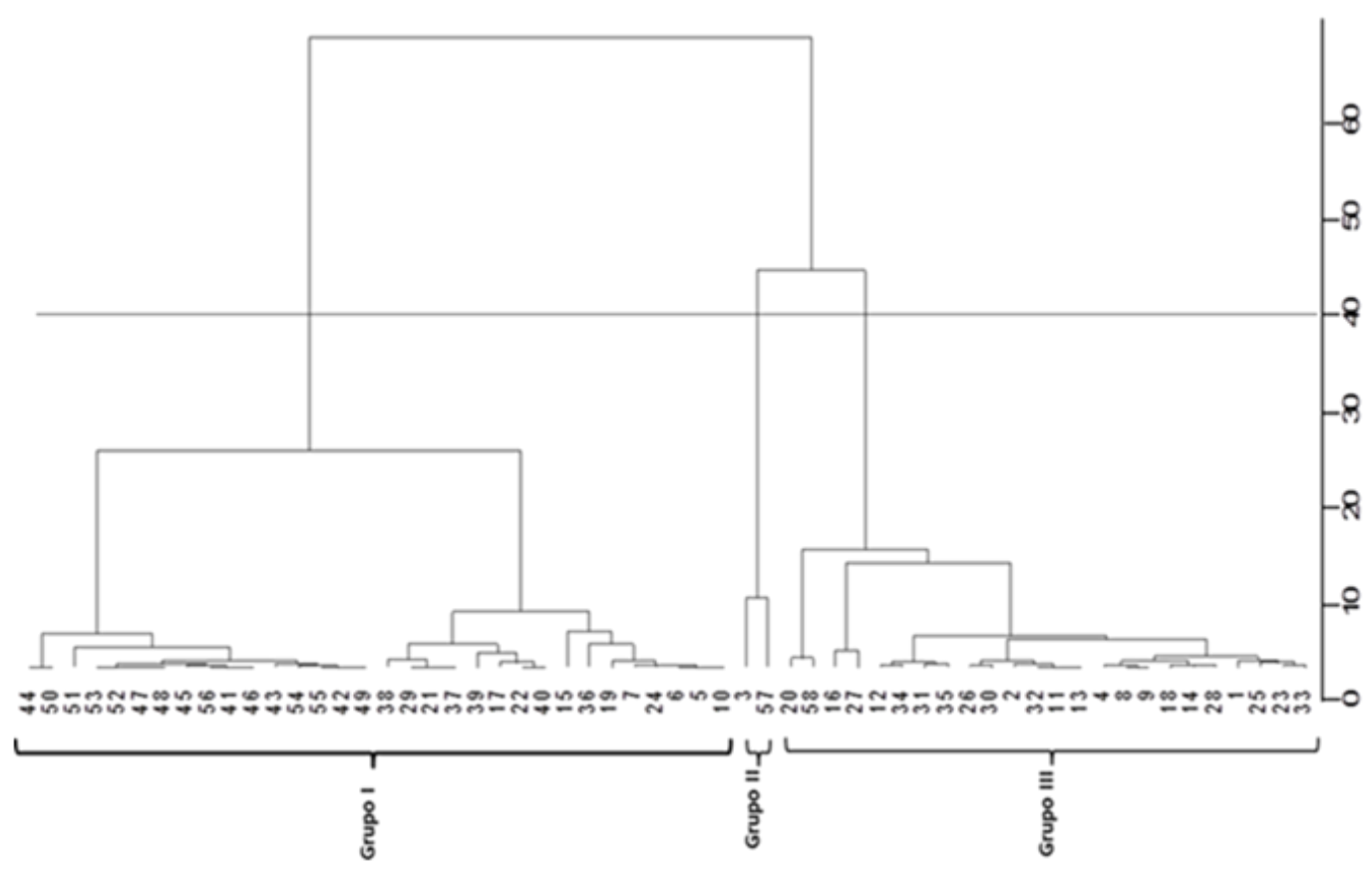

Fonte: Autores (2014).

Os genótipos foram alocados de forma semelhantes em ambos os métodos de agrupamento analisado. Resultados semelhantes foram observados por Santos et al. (2013) avaliando a divergência genética de genótipos de soja para programas de melhoramento genético para produção de grãos, encontraram a mesma formação de grupo pelo método de UPGMA e pelo Tocher, obedecendo à mesma relação de similaridade entre os genótipos. Campos et al. (2010) também observaram resultados semelhante, onde o agrupamento pelo método UPGMA foi similar ao do método de Tocher na caracterização e quantificando a divergência genética em acessos de mandioca.

Diferentes técnicas de análise multivariada têm sido usadas para estimar a divergência genética em feijão comum (Bertini et al., 2009), entre as principais estão os métodos otimização de Tocher e UPGMA, que dependem fundamentalmente de medidas de dissimilaridade estimadas previamente, como a distância Euclidiana e a distância generalizada de Mahalanobis 
(Cruz \& Regazzi, 2001).

\section{Conclusão}

Existe variabilidade genética entre os genótipos de feijão comum avaliados, e os genótipos 3 (BG-UNEMAT-11) e 57 (TB 02-23) apresentaram menor número de dias para florescimento (31 dias) e menor ciclo da cultura (73 a 82 dias), sendo os mais indicados para programas de melhoramento genético visando precocidade.

\section{Referências}

Bertini, C. H. C. M., Teófilo, E. M., \& Dias, F. T. C. (2009). Divergência genética entre acessos de feijão-caupi do banco de germoplasma da UFC. Revista Ciência Agronômica, 40(1), 99-105.

Bonett, L. P., Gonçalves-Vidigal, M. C., Schuelter, A. R., Vidigal Filho, P. S., Gonela, A., \& Lacanallo, G. F. (2006). Divergência genética em germoplasma de feijoeiro comum coletado no estado do Paraná, Brasil. Semina: Ciências Agrárias, 27(4), 547-560.

Buratto, J. S., Moda-Cirino, V., Júnior, N. D. S. F., Prete, C. E. C., \& de Faria, R. T. (2007). Adaptabilidade e estabilidade produtiva em genótipos precoces de feijão no estado do Paraná. Semina: Ciências Agrárias, 28(3), 373-380.

Campos, A., Zacarias, A., Costa, D., Neves, L., Barelli, M., Sobrinho, S., \& Luz, P. (2010). Avaliação de acessos de mandioca do banco de germoplasma da UNEMAT Cáceres-Mato Grosso. Revista Trópica: Ciências Agrárias e Biológicas, 4(2), 44-54.

Cargnelutti Filho, A., Ribeiro, N. D., Reis, R. C. P. D., Souza, J. R. D., \& Jost, E. (2008). Comparação de métodos de agrupamento para o estudo da divergência genética em cultivares de feijão. Ciência Rural, 38(8), 2138-2145.

Cargnelutti Filho, A., Ribeiro, N. D., \& Jost, E. (2006). Número necessário de experimentos para a comparação de cultivares de feijão. Ciência Rural, 36(6), 1701-1709.

Chiorato, A. F., Carbonell, S. A. M., Bezerra, L. M. C., Esteves, J. A. D. F., Gonçalves, J. G. R., Silva, D. A. D., ... \& Gallo, P. B. (2020a). IAC 1849 Polaco: carioca common bean cultivar with an early maturity and tolerance to seed darkening. Crop Breeding and Applied Biotechnology, 20 (3), e30232036.

Chiorato, A. F., Gonçalves, J. G. R., Silva, D. A. D., Carvalho, C. R. L., Esteves, J. A. D. F., Reis, L. L. B., ... \& Carbonell, S. A. M. (2020b). IAC Veloz: a new early-cycle black bean cultivar. Crop Breeding and Applied Biotechnology, 20(3), e25412034.

Companhia Nacional de Abastecimento - CONAB. (2019). Análise Mensal-Feijão [internet]. Brasília, DF: Conab.

Costa, J. G. C. \& Zimmermann, M. J. O. (1988). Melhoramento genético. In: Zimmermann, M. J. O.; Rocha, M. \& Yamada, T. (Org). Cultura do feijoeiro: fatores que afetam a produtividade. Piracicaba: Associação Brasileira para a Pesquisa da Potassa e do Fosfato, $229-245$.

Cruz, C. D. \& Regazzi, A. J. Modelos biométricos aplicados ao melhoramento genético. Viçosa: UFV, 390.

Cruz, C. D. (2013). Genes: a software package for analysis in experimental statistics and quantitative genetics. Acta Scientiarum Agronomy, 35(3), 271-276.

Dalla Corte, A., Moda-Cirino, V., \& Destro, D. (2002). Adaptability and phenotypic stability in early common bean cultivars and lines. Crop Breeding and Applied Biotechnology, 2(4), 525-534.

Food and Agriculture Organization of the United Nations - FAO. (2019). The global economy of pulses. Rome: Fao.

Faria, A. P., Moda-Cirino, V., Buratto, J. S., Silva, C. F. B. D., \& Destro, D. (2009). Interação genótipo x ambiente na produtividade de grãos de linhagens e cultivares de feijão. Acta Scientiarum. Agronomy, 31(4), 579-585.

Frota, A. B.; Freire Filho, F. R.; Côrrea, M. P. F. (2000). Impactos socioeconômicos das cultivares de feijão-caupi na região Meio-Norte do Brasil. Teresina: Embrapa Meio-Norte.

Kvitschal, M. V. (2008). Caracterização e divergência genética de germoplasma de mandioca-de-mesa da região urbana de Maringá, Paraná. Tese de doutorado, Universidade Estadual de Maringá, Maringá, PR, Brasil.

Lopes, N. F., Oliva, M. A., Cardoso, M. J., Gomes, M. M. S., \& Souza, V. F. (1986). Crescimento e conversão da energia solar em Phaseolus vulgaris L. Submetido a três densidades de fluxo radiante e dois regimes hídricos. Revista Ceres, 33(186), 142-164.

Neves, S. M. A., Nunes, M. C. M., \& Neves, R. J. (2011). Caracterização das condições climáticas de Cáceres/MT-Brasil, no período de 1971 a 2009: subsídio às atividades agropecuárias e turísticas municipais. Boletim Goiano de Geografia, 31(2), 55-68.

Oliveira, F. J. D., Anunciação Filho, C. J. D., Bastos, G. Q., \& Reis, O. V. D. (2003). Divergência genética entre cultivares de caupi. Pesquisa Agropecuária Brasileira, 38(5), 605-611.

Rao, R. C. (1952). Advanced statistical methods in biometric research. New York: J. Willey.

Ribeiro, N. D., Junior, L. H., \& Possebon, S. (2004). Variabilidade genética para ciclo em feijão dos grupos preto e carioca. Revista Brasileira Agrociência, 10(1), 19-29. 
Research, Society and Development, v. 10, n. 6, e35410615951, 2021

(CC BY 4.0) | ISSN 2525-3409 | DOI: http://dx.doi.org/10.33448/rsd-v10i6.15961

Ribeiro, N. D., Londero, P., Junior, L. H., Poerch, N., \& Cargnelutti Filho, A. (2005). Dissimilaridade genética para teor de proteína e fibra em grãos de feijão dos grupos preto e de cor. Revista Brasileira Agrociência, 11(2), 167-173.

Santos, E. R., dos Santos, A. F., Capone, A., dos Santos, W. R., Moura, S. G., \& Barros, H. B. (2013). Dissimilaridade genética entre genótipos de soja cultivados em várzea irrigada no período de entressafra. Journal of Biotechnology and Biodiversity, 4(3), 222-231.

Santos, H. G., JACOMINE, P. K. T., Dos Anjos, L. H. C., De Oliveira, V. A., LUMBRERAS, J. F., COELHO, M. R., ... \& CUNHA, T. J. F. (2018). Sistema brasileiro de classificação de solos. Brasília, DF: Embrapa.

Silva, F. B., Ramalho, M. A. P., \& Abreu, Â. D. F. B. (2007). Seleção recorrente fenotípica para florescimento precoce de feijoeiro'Carioca'. Pesquisa Agropecuária Brasileira, 42(10), 1437-1442.

Silva, S. C. \& Didonet, A. D. (2005). Cultivo do feijão irrigado na região noroeste de Minas Gerais. Brasília, DF: Embrapa Arroz e Feijão. 